\title{
Self-Interest and Other-Orientation in Motivating Organizational Citizenship Behavior
}

Fatme A Ahmad*

Department of Business Administration, Lebanese American University, Chouran Beirut, Lebanon

\begin{abstract}
This paper investigates the effect of self and other-oriented behaviors on motivating organizational citizenship behaviors in an organization. Employees vary in the strength of their self-oriented and other-oriented motives. It is believed that people high on other orientation are more likely to engage in organizational citizenship behavior; however, it has been noticed that even people high on self-orientation are willing to participate in organizational citizenship behaviors. This paper shows that organizational citizenship behaviors are essential for the success and continuity of any business.
\end{abstract}

\section{Keywords: Motivating; Self-interest; Citizenship; Organizational}

\section{Introduction}

The transformation in organizational environs, their consequential innovations, and flexibility are accentuated, which makes it essential to necessitate voluntary behavior from members of an organization. For that reason, an organization should be capable of shifting its members' attitudes and behaviors from relatively egoistic behaviors to more organization development oriented. With regard to this subject, many researchers have paid attention to organizational citizenship behavior (OCB).

In an organization every employee is expected to implement certain roles as specified by job descriptions and superior's decisions. However, sometimes workers perform certain tasks and behaviors above and beyond the call of duty. Such act is termed as organizational citizenship behavior which is defined by Organ [1] as a discretionary and explicit behavior that's not recognized by the company's formal reward system, yet promotes the efficiency and effectiveness of the organization. Organizational citizenship behavior has garnered great academic attention due to its considerable positive impact on the organization, enhancing organizational effectiveness from 18 to $38 \%$ across different measurement scopes [2].

Knowing that these behaviors are neither required nor formally rewarded, then why do workers engage in OCB? The reasons behind performing such behaviors may be driven by either self-interest or other-oriented incentives. In fact, humans are naturally born with an innate propensity to be primarily concerned with their self-interests, and their main motive underlying social or organizational citizenship behavior is to protect and enhance their egoisms. However, this doesn't contradict with the idea that sometimes performing some noble activities and volunteering in citizenship behaviors may be due to other-orientation.

The purpose of this paper is to provide a definition for organizational citizenship behavior and highlight the way it enhances organizational performance and well-being. It further focuses on how taking a specific perspective can contribute to a more complete picture of what encourages OCB in the workplace. Throughout the course of discussion, the correlation between self-interest and other-orientation is also presented.

\section{Literature Review}

The theory of Organizational Citizenship Behavior (OCB) was originally stated by Chester Barnard as the willingness of workers in organizations to collaborate [3]. Katz [4] subsequently defined OCB as a bundle of "innovative and spontaneous behaviors" that is different from the more compulsory role performance. The distinction of this theory is based on whether the behaviors are listed in an employee's job description, well known as in-role performance, or whether they're not a part of his or her job description, known as extra-role performance. The origin of OCB is attributed to classical management theorists and experts $[3,5,6]$ who indicated that cooperative behaviors prolonging beyond a worker's job requirements are essential and vital for the thriving of an organization.

Empirical studies have initially concentrated on identifying the predictors behind organizational citizenship behavior. Indeed, analyses described a wide range of these predictors that can be classified into two broad classes, known as other-oriented job attitudes and selfinterest individual behaviors $[7,8]$. Research has found substantial support and consensus for a positive relationship between otherorientation and various forms of OCB. However, little evidence has been found regarding the relationship between self-interest and OCB. In addition, while the social exchange theory provides a framework for understanding the relationship between other-orientation and OCB $[9,10,11]$, there's no equivalent association between individual interests and OCB. Therefore, it's not clear as to how individual desires and other-orientation might jointly influence OCB.

\section{Organizational citizenship behavior}

Organizational citizenship behavior is the technical psychological term for what can be defined as the assemblage of individual behaviors in a group setting. OCB was primarily defined as "an individual behavior which is not rewarded by a formal reward system, but that, when combined with the same behavior in a group, results in effectiveness" [1]. There are numerous situations in organizations when employees support their fellow employees an act that's not part

*Corresponding author: Fatme A. Ahmad, Department of Business Administration Lebanese American University, Chouran Beirut, Lebanon, Tel: + 9611786456 , E-mail: fatme.ahmad@lau.edu

\section{Received April 16, 2018; Accepted April 20, 2018; Published April 30, 2018}

Citation: Ahmad FA (2018) Self-Interest and Other-Orientation in Motivating Organizational Citizenship Behavior. Review Pub Administration Manag 6: 234. doi:10.4172/2315-7844.1000243

Copyright: @ 2018 Ahmad FA. This is an open-access article distributed under the terms of the Creative Commons Attribution License, which permits unrestricted use, distribution, and reproduction in any medium, provided the original author and source are credited. 
of their job requirements. This assistance is spontaneous and does not lead to any formal reward. Nowadays, researchers are more concerned with studying the subject of organizational citizenship behavior, due to fundamental variations in the nature of work and the workplace. In the business world, OCB has been associated with work efficiency, employee efficacy, and other aspects which can have an impact in the short or long term.

Organizations gain from encouraging employees to engage in $\mathrm{OCB}$, because it has been shown to be indeed correlated to organizational performance. In other words, these behaviors correspond to cost reductions, rates of turnover, and absenteeism but enhancements in effectiveness, profitability, efficiency, and customer [2]. When skillful employees show organizational citizenship behavior, they might mentor others and transmit their skills and know how to apprentice employees whose productivity might thus improve exponentially.

Moreover, organizational citizenship behaviors might smooth the progress of the identification of intuitive and innovative solutions to improve the whole organization. These behaviors might promote positive emotions and thoughts among employees, including solidity and morale. In addition, Organ, Podsakoff, MacKenzie [12] have offered the following propositions OCB seem to have such gripping effects on the individual and the success of an organization.

- Enhance productivity by helping others.

- Free up resources to facilitate cohesiveness.

- Attract and retain good employees through building and sustaining a pleasant and supportive working environment.

- Create social capital through better communication and stronger networks.

Therefore, although OCB are spontaneous initiatives taken by employees, companies are able to endorse these behaviors in their workplace through employee motivation, as well as giving them the opportunity to display OCB by creating an environment that not only allows for but is conducive and highly supportive of such behaviors [12]. Management should also be aware of OCB and consider having these distinguished behaviors included in the performance assessments in order to highly encourage them among workers.

Traditionally, researchers have claimed that social exchange relationships resulting from positive job attitudes or cognitions such as effective commitment, perceived support, and fairness encourage employee citizenship behavior [13]. That is, workers are more inclined to "go the extra mile" when they feel that the organization is treating them well and fairly.

\section{Discussion}

The Social Exchange Theory describes the voluntary exchange of benefits that arise between two [14]. In this context, organizational citizenship behavior is a form of benefit delivered by individuals within the social exchange relationship. Based on this theory, rules and norms of reciprocity have a crucial role in motivating the exchange of reimbursements between these parties. This principle claims that the recipient of a benefit from another party should deliver a benefit in kind. In other words, reciprocity motivates moral behaviors, such as helping, and creates an ethical obligation to give back that behavior in return. Moreover, functioning as an extensively shared societal norm, reciprocity creates an expectation that benefits will be returned.

Organizational citizenship behaviors appear in different shapes such as allegiance, assisting others, and organizational compliance [8]. Organizations promote employees who are willing to contribute their work and capabilities to the organization even though that's not officially required of them.

\section{Common types of organizational behavior}

Dennis Organ's 1988 study on OCB classified the notion into five ordinary behaviors. Organ's study recommended that, when these common behaviors are displayed in a group milieu, it'll lead to effectiveness. This indicates that the five most familiar organizational citizenship behaviors will lead to higher efficiency and work efficacy. Even though psychologists have identified many other widespread positive organizational citizenship behaviors, those identified by Organ are still deemed to be the most worth mentioning. The five most familiar behaviors, as identified by Dennis Organ, are: Altruism, courtesy, sportsmanship, conscientiousness and civic virtue.

Altruism: Altruism is the desire to help or give a hand to another individual, without expecting a reward in reimbursement for that assistance. In a workplace, altruistic behavior is normally linked to the work or project that the business group is working on. Altruism in the place of work leads to efficiency and efficacy because it promotes good employee relations. It can also lessen the stress load on other employees, such as those who are snowed under devoid of any help; actions which will in turn amplify productivity.

Courtesy: Courtesy is described as is well-mannered and caring behavior towards others. In an organization, courtesy is frequently revealed through behaviors such as showing interest in personal subjects that a colleague has brought up in the past. Courtesy promotes social relations among employees, which improves the work environment.

Sportsmanship: Sportsmanship is described as displaying zero negative behavior when something doesn't go as planned or when something is perceived as irritating, complicated, or negative. In the workplace, sportsmanship is typically connected to possible grievance about work or workloads and to a negativity surrounding work-related out of the blue outcomes.

Conscientiousness: Conscientiousness is the behavior that suggests a sensible level of discipline and self-regulation, which expands beyond the minimal requirements estimated in that situation. Conscientiousness is observed when an employee not only meets his or her employer's requirements but goes beyond them.

Civic virtue: Civic virtue is the behavior which demonstrates how well a person represents an organization with which they are allied, and how well that person sustains his or her organization outside of an official duty. Civic virtue supports a sense of affinity within a business setting, which has been shown to be connected to job performance and employee satisfaction. Employees with a stronger bond with their employment place are more expected to be fruitful and effective workers, when contrasted to those who don't share a sense of belonging.

Organ [11] then extended this model by adding two types; peacekeeping serves as an intermediary to ratify resolutions to disagreements and cheer leading is the offering of appraisal and encouragement. Later a more up to date OCB framework was built up by Williams and Anderson [15]. Organizational citizenship behavior constructs were assembled based on anticipated target or direction of the behavior. OCBI denotes behaviors intended to help co- workers and OCBO designates behaviors that primarily benefit the organization.

The OCBI categories are assumed to comprise altruism, sustaining 
the peace, and cheer leading behaviors; behaviors seen to reveal intentions of assisting others.

The OCBO classes are conscientiousness, civic virtue and sportsmanship as identified by Organ [1] in addition to organizational allegiance [16], support and commitment to the organization's objectives [17], job devotion [18], taking charge [19] and promoting the company image [20].

Most of the literature on organizational citizenship behavior has focused on helping colleagues, being punctual, and attending nonrequired work functions, as opposed to more substantial behaviors rooted in a desire to help one's organization develop, grow, and improve. Thus, although taking charge is a type of extra role behavior, it differs meaningfully from OCB and related constructs such whistle blowing, role innovation, and personal initiative.

\section{Theory of other-orientation}

Other-orientation is known as the degree to which a person is concerned with the well- being of others. Being other-oriented necessitates a shift from "me first" to "you first" and a balancing behavior which considers the needs and well-fare of others. This principle applies inside the place of work; the other-orientation theory implies that workers that are high on other orientation are less likely to consider possible self-consequences while making decisions and performing duties.

Altruism is considered as a motivation to increase another individual's welfare and is assumed to be driven by a selfless concern for others [21]. In regard with this conceptualization, there exists considerable and practical support demonstrating that people incur a significant cost to the self in order to help and benefit others [22]. Acts such as helping, cooperating, sharing, and volunteering are forms of altruism or pro-social behaviors. When employees perform such positive and social behaviors, they often sacrifice their time, effort, or any type of input, in order to produce and maintain the harmony and well-being of others.

Often, the targets are individuals with whom other-oriented organizational members cooperate while performing organizational citizenship behaviors with the aim of benefiting the target directly. This target might be either a co-worker (supervisor, colleague, or subordinate) or a customer of organizational products and services. Besides, Staw [23,24] further suggests that employee citizenship behaviors don't have to be restricted to actions toward individuals but can also include actions toward the organization as a whole. This means that individuals would be offering time, effort, and other personal resources and, in this sense, sacrificing some portion of their own interests and inputs for the good of the organization.

Several examples of other-oriented behaviors that "go beyond" listed role requirements are: cooperating with co-workers, taking action when compulsory to shield the organization from any unexpected nuisance, suggesting means to improve the company, applying selfdevelopment and preparation for higher levels of organizational responsibility, and positively promoting the organization to strangers [25]. The organization is more apt to thrive when these behaviors are applied because they boost the organization's ability to endure and achieve its goals. Although these actions are crucial for organizational endurance and continuity, they're difficult or even impossible to endorse as part of an individual's formal job and role requirements. Thus, they represent forms of altruism and other oriented actions; that is, means to which an employee can act spontaneously and voluntarily to promote the organizations interests.

\section{Self-orientation}

When an employee is perceived as self-oriented, this means that this employee is excessively concerned with his/her own needs, desires or welfare. By doing so, an individual ignores and pays no attention to the interests of co-workers in order to achieve own desires and fulfillment. This employee becomes completely narcissistic, constantly chasing self-glory and clamoring to take credit. Because these types of individuals regularly thirst for achievement, many narcissists are higher achievers. They get acknowledged, rewarded, praised, and promoted.

Employee's long-term success depends on others so orientating one's self in their opinion is a smart strategy, after all. Lavelle [13] mentioned that in organizations, the decisions and efforts of employees to engage in certain forms of organizational citizenship behaviors may be driven by instrumental and career-related motives. For instance, volunteering often offers opportunities for workers to make new contacts that can help them achieve several career goals. In fact, such self-concerned purposes were found to explain why a number of college students looking for fulltime jobs are often stimulated to volunteer in order to enhance their resume rather than being concerned with the cause itself. Also, attending a community event, that is a form of OCB not only enriches the company's image but also delivers an ultimate chance for the employee to develop contacts that may be of a great benefit when creating future business or employment opportunities. Furthermore, faculty decisions to join non-required advisory board meetings may be influenced by the opportunity to make connections in the hopes of securing future data collection sites, new jobs in the industry, or even for advancements within the institution. The above grounds suggest that job-related incentives may be particularly predictive of employee citizenship behaviors.

Some non-compulsory activities can provide further opportunities to learn and adopt new ideas, gain unique perceptions, and acquire essential skills and capabilities. According to Omoto and Snyder [26], understanding motives better predicted the time people spent volunteering for an AIDS service organization. In other words, applying organizational citizenship behaviors by volunteering in organizational committee work can facilitate obtaining new information and perspectives on topics of particular interest to staff. Such decisions to involve in organizational citizenship behaviors may be determined by learning and understanding the goals of a worker. In contrast, this role seems less applicable to individually directed forms of citizenship such as altruism, where the goal of employee is to provide information and assistance to others.

OCB also create opportunities for people to meet their social needs by getting along with others who view volunteerism favorably and build interpersonal relationships. Volunteerism may also be seen as a way to make networks, especially for those new to a community. In this context, Farmer and Fedor [27] claimed that social relations is directly associated with the amount of time people spent volunteering. Similarly, interactions with other employees in workplace can help fulfill social needs and strengthen interpersonal relations. In fact, most forms of OCB involve interactions with others and thus, the decision to perform these behaviors may be extremely driven by social desires. Therefore, social influence may affect employee decisions to engage in several forms of OCB.

The decision to volunteer can be the result of a strong desire to feel needed, feel dominant, and raise self-esteem. Moreover, volunteering may reflect great striving linked to personal growth and enhancement. Okun, Barr, and Herzog [28] supported the latter role by stating that 
ego-enhancing drives predict the frequency of volunteering in several fields. Employees may also seek to perform activities that will enrich their positive self-regard. Participating in committees serves as an illustration since it provides an opportunity for the individual to be a decision maker and to enhance the factors that can contribute to feelings of importance. In other words, helping co-workers with their problems can boost self-esteem and provide the person with an indication that others need him or her. Moreover, by demonstrating to others that you have the skills necessary to help solve their problems can be ego enhancing. The above line of reasoning suggests that OCB might be associated with ego- enhancement incentives.

\section{Variations in self-concern and other-orientation}

Employees vary in the strength of their self-oriented motives and similarly their other- orientation ones. Researchers in psychology and the organizational sciences took both a self- concern and otherorientation one into consideration to correspond to the end points of a bipolar continuum. Likewise, according to De Dreu and Nauta [29] selfinterest and other-orientation are conceptualized as independent facets that individuals can be high (or low) on separately or simultaneously. Even current work on other-orientation assumes that having higher other- orientation entails a lower self-concern [30,31]. In accordance to theoretical and empirical work, self-concern and other-orientation are orthogonal and independent. Therefore, variation in self-orientation doesn't necessarily have an effect on other- orientation and vice versa. An individual can be high on self-interest and other-orientation, low on both, or high on one continuum and low on the other.

A support for this suggestion results from considering the antecedents of self-concern and other-orientation. Variation in selforientation may be due to personality or situational demands and restraints. For example, the more individuals view themselves as independent and self- directed, the more they are to have high selfinterest [32]. Similarly, people with higher achievement motivation and a stronger performance orientation may likely have higher self-concern [33]. As with self-concern, differences in other- orientation may result from personality or situational demands and restrictions; however, these are quite different from the ones determining self-concern. Thus, the more individuals see themselves as interdependent and part of a social system, the higher their other-orientation will be [32].

\section{Conclusion}

It is believed that people high on other orientation are more likely to engage in organizational citizenship behavior since they possess the "helping others" gene in their DNA; however, it has been noticed that even people high on self-orientation are willing to participate in OCB. The engagement of self-oriented people on the other hand is driven by relatively egoistic drives that impel them to give in order to receive praise and admiration. Organizational Citizenship Behaviors in their various shapes and forms are essential for what impact these behaviors have on businesses. An organization with the right OCB features will definitely thrive regardless of its employees inner drive directions. Important questions remain regarding whether two forms of OCB (OCBI and OCBO) are related differently with certain individual-level antecedents and consequences.

\section{References}

1. Organ DW (1988) Organizational citizenship behavior: The good soldier syndrome. Lexington Books, Lexington, MA, USA. 14: 294-297.

2. Podsakoff NP, Whiting SW, Podsakoff PM, Blume BD (2009) Individual- and organizational-level consequences of organizational citizenship behaviors: A metaanalysis. J Appl Psychol 94: 122-141.
3. Barnard $\mathrm{Cl}$ (1938) The functions of the executive. Harvard University Press Cambridge, MA, USA.

4. Katz D (1964) Motivational basis of organizational behavior. Behav Sci 9: 131146.

5. Katz D, Kahn RL (1966) The social psychology of organizations. Soc Forces 46: 1 18-119.

6. Roethlisberger FJ, Dickson WJ (1939) Management and the worker. Harvard University Press, Cambridge, MA, USA.

7. Organ DW, Ryan K (1995) A meta-analytic review of attitudinal and dispositiona predictors of organizational citizenship behavior. Pers Psychol 48: 775-802.

8. Podsakoff PM, MacKenzie SB, Paine JB, Bachrach DG (2000) Organizational citizenship behaviors: A critical review of the theoretical and empirical literature and suggestions for future research. J Manage 26: 513-563.

9. Cropanzano R, Rupp DE, Byrne ZS (2003) The relationship of emotional exhaustion to work attitudes, job performance, and organizational citizenship behaviors. J Appl Psychol 88: 160-169.

10. Konovsky MA, Pugh SD (1994) Citizenship behavior and social exchange Acad Manage J 37: 656-669.

11. Organ DW (1990) The motivational basis of organizational citizenship behavior In B.M. Staw \& L.L. Cummings (Eds.), JAI Press, Greenwich, CT, USA. Res Organ Behav 2: 43-72.

12. Organ DW, Podsakoff PM, MacKenzie SB (2006) Organizational citizenship behavior: Its nature, antecedents, and consequences. Pers Psychol 59 484-487.

13. Lavelle JJ (2010) What motivates OCB? Insights from the volunteerism literature. J Organ Behav 31: 918-923.

14. Lester SW, Meglino BM, Korsgaard MA (2008) The role of other orientation in organizational citizenship behavior. J Organ Behav 29: 829-841.

15. Williams LJ, Anderson SE (1991) Job satisfaction and organizational commitment as predictors of organizational citizenship and in-role behaviors. J Manage 17: 601-617.

16. Graham JW (1991) An essay on organizational citizenship behavior. J Emp Resp R 4: 249-270.

17. Borman WC, Motowidlo SJ (1993) Expanding the criterion domain to include elements of contextual performance. In: Schmitt N, Borman WC (Eds) Personnel selection in organizations. Jossey-Bass, San Francisco, CA, USA pp: 71-98.

18. Van Scotter JR, Motowidlo SJ (1996) Interpersonal facilitation and job dedication as separate facets of contextual performance. J Appl Psychol 81: 525-531.

19. Morrison EW, Phelps CC (1999) Taking charge at work: Extrarole efforts to initiate workplace change. Acad Manage J 42: 403-419.

20. Farh JL, Zhong CB, Organ DW (2004) Organizational citizenship behavior in the People's Republic of China. Organ Sci 15: 241-253.

21. Batson CD, Powell AA (2003) Altruism and prosocial behavior. In: Weiner IB, Millon T, Lerner MJ (Eds.) Handbook of Psychology pp: 464-484.

22. Camerer C, Thaler RH (1995) Anomalies: Ultimatums, dictators and manners J Econ Perspect 9: 209-219.

23. Staw BM (1983) Motivation research versus the art of faculty management Rev High Edu 6: 301-321.

24. Straw BM (1984) Organizational behavior: A review and reformulation of the field's outcome variables. Ann Rev Psychol 35: 627-666.

25. Brief AP, Motowidlo SJ (1986) Pro-social organizational behaviors. Academy Manage Rev 11: 710-725.

26. Omoto AM, Snyder M (1995) Sustained helping without obligation: Motivation, longevity of service, and perceived attitude change among AIDS volunteers. J Pers Soc Psychol 68: 671-686.

27. Farmer SM, Fedor DB (2001) Changing the focus on volunteering: An investigation of volunteers' multiple contributions to a charitable organization. J Manage 27: 191-211. 
Citation: Ahmad FA (2018) Self-Interest and Other-Orientation in Motivating Organizational Citizenship Behavior. Review Pub Administration Manag 6: 234. doi:10.4172/2315-7844.1000243

Page 5 of 5

28. Okun MA, Barr A, Herzog AR (1998) Motivation to volunteer by older adults: A test of competing measurement models. Psychol Aging 13: 608-621.

29. De Dreu CW, Nauta A (2009) Self-Interest and other-orientation in organizational behavior: Implications for job performance, prosocial behavior and personal initiative. J Appl Psychol 94: 913-926.

30. Meglino BM, Korsgaard MA (2004) Considering rational self-interest as a disposition: Organizational implications of other orientation. J Appl Psychol 89: 946-959.
31. Meglino BM, Korsgaard MA (2007) The role of other orientation in reactions to job characteristics. J Manage 33: 57-83.

32. Markus HR, Kitayama S (1991) Culture and the self: Implications for cognition, emotion, and motivation. Psychol Rev 98: 224-253.

33. McClelland DC (1985) How motives, skills, and values determine what people do. Ame Psychol 40: 812-825. 